\title{
Silvia Bleichmar y las paradojas psicoanalíticas de las masculinidades contemporáneas
}

\author{
Silvia Bleichmar and the Psychoanalytical Paradoxes of Contemporary Masculinities \\ Omar Acha \\ Centro de Investigaciones Filosóficas, Universidad de Buenos Aires - CONICET, Argentina \\ omaracha@gmail.com
}

\section{Resumen:}

La psicoanalista Silvia Bleichmar desarrolló una obra original en el ámbito psicoanalítico argentino. En el contexto general de las perspectivas de Jean Laplanche, Bleichmar extendió sus preocupaciones, siempre con un interés específico en la clínica, a propósito de una concepción crítica de las masculinidades como paradoja. En ese planteo introdujo discusiones sobre los sexos, los géneros y las sexualidades, que poseen interés para el pensamiento psicoanalítico y, más allá de él, para la teoría e investigación sociales. En este trabajo se despliega una lectura de las elaboraciones de Bleichmar como momento de la historia del nexo conflictivo entre psicoanálisis y crítica del sistema sexo-género, en particular a lo que la teórica argentina denominó el carácter paradojal de las masculinidades contemporáneas.

Palabras clave: Psicoanálisis, Subjetividades, Sexualidades, Masculinidades.

\section{ABSTRACT:}

The psychoanalyst Silvia Bleichmar developed an original work in the Argentinian psychoanalytic context. In the general framework of Jean Laplanche's perspectives, Bleichmar has extended her concerns, always with a specific interest in the clinic, regarding a critical conception of masculinities as a paradox. In that approach, she has introduced discussions about the sexes, genders and sexualities, which have an interest in psychoanalytic thinking and, beyond it, for social theory and research. In this work, a reading of Bleichmar's elaborations is displayed as a moment in the history of the conflictive link between psychoanalysis and criticism of the sex-gendered system; in particular, what the Argentinian theoretician called the paradoxical character of contemporary masculinities.

KEYWORDS: Psychoanalysis, Subjectivities, Sexualities, Masculinities.

\section{INTRODUCCIÓN}

Las posibilidades, obstáculos y condiciones del empleo del saber psicoanalítico "fuera" de su territorio usualmente considerado el propio - esto es, la clínica- ha suscitado una densa bibliografía. No hay ámbito de la producción discursiva en las "ciencias humanas" o en las "humanidades" que haya permanecido indiferente al mundo nocional inaugurado por Sigmund Freud. De la antropología a la historiografía y la filosofía, de la sociología a la pedagogía, de la criminología a la politología, de la literatura a los estudios culturales, el psicoanálisis ha perforado una y otra vez las fronteras de su campo específico y ha permeado terrenos que, en lo referente a las matrices del saber, no le fueron originarios. Sin embargo, la pertinencia de tales pasajes, desplegados a veces con entusiasmo, ha sido con frecuencia objeto de impugnaciones y todavía hoy, ante una nueva crisis del psicoanálisis, sus estatus epistemológicos y culturales son inciertos. ${ }^{1}$

La "extensión" del psicoanálisis, término de impronta lacaniana, introduce una variación en la óptica de los pasajes transdisciplinares, aunque esa novedad todavía exija una mayor elaboración. No obstante, la extensión se distingue de la aplicación por cuanto introduce desde su misma concepción, implícitamente, la puesta en 
suspenso de la validez normativa de las barreras conceptuales heredadas. ${ }^{2}$ Como sea que fuere, la controversia entre aplicación y extensión no ha sido saldada, y es factible proponer nuevas versiones de la subversión de la doxa psicoanalítica que ese dualismo, quizá, empobrece. Por otra parte, parece atinado no disolver las vallas disciplinares, como puede suponer una lectura demasiado rápidamente inspirada en los trabajos de Jacques Derrida, sobre todo en La tarjeta postal, en torno a la autoridad en psicoanálisis y sus premisas metafísicas (Derrida, 2001).

Me interesa insistir sobre algunos temas de los pasajes fronterizos del saber psicoanalítico para el pensamiento crítico de la sociedad. El ámbito elegido es el análisis del carácter inherentemente paradojal de la diferenciación sexual y, más precisamente, de las masculinidades. Quise evitar una discusión solo conceptual, pues me parece que esa estrategia de análisis suele rendir una productividad decreciente. Quizá sea más fértil para el debate el estudio de esta cuestión a través de la lectura de un ejercicio situado del empleo de categorías psicoanalíticas, tal como el ensayado por la psicoanalista argentina Silvia Bleichmar (1944-2007) a propósito de las masculinidades en términos paradojales. La obra de Bleichmar permitirá acceder a un cuerpo documental en el que se observará el trabajo concreto del uso de una versión específica del psicoanálisis para reflexionar sobre este aspecto de lo sexual y subjetivo.

La preocupación social y política del psicoanálisis en la Argentina está lejos de constituir una rareza. Numerosos estudios históricos han reconstruido las maneras en que desde los lustros tempranos del siglo XX y por lo menos hasta el inicio de la última dictadura militar, en 1976, la perdurabilidad de ese compromiso del psicoanálisis con su época. Después de 1983, dicho compromiso fue rearticulado en una nueva situación. El itinerario de Silvia Bleichmar pertenece a esa fase de una historia prolongada y discontinua.

Comenzaré este artículo con un recorrido por la obra teórica y clínica de Bleichmar desarrollada durante las décadas de 1980 y 1990. Me interesa mostrar que las extensiones del horizonte conceptual freudiano para el análisis social del cambio de siglo no emergieron sin importantes precedentes. Destacaré que el desarrollo de su pensamiento psicoanalítico, inescindible de un interés clínico, estuvo siempre articulado con una interrogación sobre la historia como proceso supra- e inter-individual y temporalizado. La segunda sección del artículo reconstruye las innovaciones conceptuales propuestas por Bleichmar para pensar activamente el desafío de las masculinidades y sus consistencias inherentemente paradojales. En relación con la asunción de lo paradojal, argumentaré que el psicoanálisis se encuentra desgarrado -justamente por sus exigencias clínicas, a las que considero vigentes mientras existan subjetividades que acudan a los tratamientos para un acompañamiento en el desfiladero de sus pasiones- entre el reconocimiento de la multiplicidad del deseo y las eficacias dolientes del síntoma.

Concluyo esta introducción con una apostilla en torno a la concepción del empleo "extra-clínico" del psicoanálisis. El recurso de un conjunto de nociones que permiten desnudar una realidad oculta ha sido en diversas ocasiones una estrategia para tornar al psicoanálisis en una hermenéutica de la verdad reprimida. En dicha comprensión, lo inconsciente, la represión, la condensación y el desplazamiento, distorsionan un mensaje que por inaceptable para la conciencia es cercenado antes de atravesar el pasaje al nivel tópico de las "representaciones-palabras". Persisten en el terreno intermedio de las "representaciones-cosa" y en un lenguaje contorsionado en el que asoman esas huellas híbridas denominadas síntomas. Se supone que un "contenido" es oprimido y un sentido "latente" pulsa el discurso que la transferencia posibilita, al menos parcialmente, liberar. Para lograrlo deben intersectarse la asociación "libre” y la "atención flotante". El gran problema de esta noción de psicoanálisis como dispositivo hermenéutico, sobre todo cuando desborda la clínica, consiste en que la nomenclatura conceptual psicoanalítica -la metapsicología- se transforma en un sistema infalible de clasificación etiológica y en una gendarmería de los significantes. Solo por brindar un ejemplo, es conocido el problema de la aplicación de las contrariedades del complejo edípico para resolver los enigmas de la sociedad, la cultura y la historia. Desde la propuesta de Ricoeur (1979) de entender a Freud como una versión de la "hermenéutica de la sospecha", han sido varias las refutaciones de dicha reducción del quehacer psicoanalítico al develamiento del sentido oculto (Žižek, 1992; Saphouan, 
1992; Dean, 2002). Figura decisiva del pensamiento de Bleichmar, Jean Laplanche (1996) ha propuesto destacar la interpretación en psicoanálisis como una "anti-hermenéutica". Su tarea consiste en "puntuar" las producciones del inconsciente y no en pretender reinscribirlas en una metapsicología a priori. Veremos de qué modo las intervenciones teóricas de Silvia Bleichmar exceden el modelo hermenéutico en una preocupación incesante por las modalidades específicas del malestar en la cultura. Hasta qué punto esa vocación de ir más allá de las evidentes zonas de necrosis en el psicoanálisis será, aquí, objeto de reflexión a propósito de las masculinidades contemporáneas.

\section{PSicoANÁLisis, CLÍNiCA E IDEOLOgÍA}

En este apartado, mostraré que las elaboraciones teórico-clínicas de Silvia Bleichmar estaban atravesadas desde su madurez por un pronunciado interés respecto de las implicancias del psicoanálisis para la reflexión social y para la comprensión crítica de la historia. Esto no es intuitivo si leemos los títulos de sus obras principales en materia psicoanalítica: En los origenes del sujeto psíquico, La fundación de lo inconsciente, o Clínica psicoanalitica y neogénesis (respectivamente: Bleichmar, 1984, 22a [1993], y 21 [1999]). Sin embargo, las evidencias del mencionado interés están presentes en su tesis doctoral en psicoanálisis defendida a principios de los aos 198 con la supervisión de Jean Laplanche en la Universidad de París VIII. El libro de allí surgido, En los orígenes del sujeto psíquico, es un estudio cuyas derivaciones teóricas exceden la temática específica del psicoanálisis infantil. Su argumento afecta al conjunto del saber psicoanalítico en tanto concierne al momento fundacional de lo inconsciente, significativo incluso sin olvidar la relevancia de la temporalidad retroactiva en psicoanálisis (Nachtrglichkeit, aprs coup). Como veremos, las consecuencias nocionales atraviesan las fronteras del propio psicoanálisis.

Bleichmar inició su argumentación inscribiéndose como analista en una situación intersubjetiva: "Ser psicoanalista implica ubicarse en la serie de las generaciones" (Bleichmar, 1984, p. 17). Muy pronto explicaré el sentido de esa situación para la teoría del inconsciente y la cuestión del "goce intergeneracional”. En este momento, me interesan sus derivaciones sobre la postura de analista. Esa implicación entraña una vertiente ético-política que creo conveniente citar in extenso:

"Espero haber ayudado a todos ellos [los niños analizados] a aumentar su capacidad crítica y su independencia de pensamiento tanto respecto de sí mismos como frente al mundo que los rodea. Este descentramiento de sí mismos y la recuperación de su historia les permitirán ampliar su margen de libertad dándoles herramientas para comprender con mayor profundidad el difícil tiempo nuevo.

No creo que esto implique una propuesta educativa en sentido tradicional. Sí creo que la práctica psicoanalítica no es ajena a una ética, la que atañe a la ampliación de los márgenes de la libertad, es decir, de la libertad de pensar" (Bleichmar, 1984, p. 18).

Tal declaración de principios - de impronta ilustrada y democrática- constituye un sello habitual de la escritura de Bleichmar, quien intenta ser fiel a la misma en la formulación de una teoría del inconsciente. Dicho de otro modo, Bleichmar aspira a sostener una relevancia ética como arreglo interno del saber freudiano.

La tesis doctoral de Bleichmar se nutre diversas elaboraciones, entre las que se desplaza con soltura nada dogmática. Freud y Lacan, Klein y Winnicot, proveen nociones y perspectivas que son empleadas en un territorio fundado por el primero, pero ante el cual la lectora argentina opera conceptualmente de acuerdo a lo que entiende son las exigencias del tratamiento clínico. Su deuda mayor es con Laplanche, de quien adopta la teoría "realista" del inconsciente, la concepción de la seducción generalizada y la idea del otro materno como instancia constitutiva de la creación del inconsciente. Con Laplanche, nos hallamos ante una versión peculiar del psicoanálisis. Su planteo más conocido es la ponencia en el Coloquio de Bonneval, donde formula una contraposición al esquema lacaniano sobre la estructuración de lo inconsciente "como un lenguaje": "el 
inconsciente es condición del lenguaje" (Laplanche y Leclaire, 1969, p. 50-51). Las posteriores elaboraciones laplancheanas eluden una simetría tan clara y forjan un fundamento diferente.

Aludiré brevemente a los elementos básicos del pensamiento de Laplanche pues Bleichmar parte de ellos para desplegar una concepción autónoma cuyos alcances no pretendo siquiera sintetizar en este breve ensayo. Laplanche construye un "nuevo fundamento" del psicoanálisis retomando el camino abandonado por Freud hacia 1897 con su renuncia a la teoría de la seducción infantil, esto es, a la etiología de la histeria (y de las neurosis en general) como efecto retardado de una agresión sexual sufrida durante la infancia. Para resolver el dilema de una explicación de la universalidad del trauma infantil con efectos postergados, Freud derivó la necesidad de considerar dos fuentes fundamentales: la carga de representaciones filogenéticamente adeudadas a las generaciones pasadas y la teoría de la sexualidad infantil. Aunque la seducción no pudiera ser descartada en todos los casos, era una contingencia y no una experiencia necesaria. Ambas fuentes mencionadas hallaron su eficacia afectiva en la colisión con las variaciones pulsionales constitucionales y el grado de represión padecida.

Para Laplanche, la retirada de la teoría de la seducción debía ser revisada y revalidada de acuerdo con otro concepto de trauma. Este concepto supone una "generalización” ligada al énfasis lacaniano de la primacía del significante en la institución subjetiva (al menos en el Lacan estructuralizante del refundacional "Discurso de Roma”, en 1953). Sin embargo, Laplanche opera severas modificaciones en el planteo lacaniano: la seducción es universal por cuanto tramita un mensaje del otro que no puede ser decodificado plenamente por la asimetría primordial que enfrenta a una criatura sin inconsciente ( $\sin$ un dominio del lenguaje, aunque sí con pulsiones) con un otro adulto que ya posee un inconsciente pautado por las incertidumbres de lo sexual. La recepción del mensaje genera un "significante enigmático" por dos razones. La primera, porque la criatura carece de inconsciente, de un lenguaje incorporado, de la facultad para comprender y mellar la eficacia traumatizante del mensaje. Entonces, se desencadena una represión "originaria" como recurso defensivo. La segunda, porque el otro, cuyo propio mensaje, en cuanto está atravesado por el inconsciente y cuyos significados esenciales se le escapan, tampoco es soberano de las significaciones emitidas. Es así que el traumatismo deviene universal dada la divergencia estructural entre la criatura y el adulto, entre la carencia de inconsciente y la producción de mensajes enigmáticos (por otra parte, inescindibles de una carga sexualizante que colisiona con la configuración pulsional del infans). La teoría de la seducción configura el esquema originario de la construcción del inconsciente pues los fragmentos ininteligibles del mensaje del otro son el fundamento de la nueva tópica que permite captar la emergencia del sujeto psíquico (Laplanche, 1973, 1983, 1989, 1996; una síntesis de los aportes laplancheanos en Bleichmar, 1987).

Los conceptos de Laplanche son utilizados por Bleichmar en su tesis doctoral para evadir una dificultad en la concepción de Melanie Klein según la cual el inconsciente es "arcaico" pues ya está presente, con su carga fantasmática, en la criatura apenas nacida. En cambio, Bleichmar propone distinguir entre los trastornos que afectan a la criatura antes de su inclusión en lo propiamente sintomático, pues esto supone el inconsciente, de los sintomas que lo conmueven después de la configuración de una tópica preconsciente-inconsciente. La criatura se encuentra arrojada en un proceso de estructuración intersubjetiva. Antes que un pasaje metafórico entre un tiempo y otro, como es usual en el lacanismo, Bleichmar sigue a Laplanche en el término "metábola", que refiere a la incorporación parcial y constituyente del mensaje enigmático. Dicha incorporación tiene derivas impredecibles en sus efectos concretos de subjetivación. Por lo tanto, el inconsciente de allí surgido no podría ser entendido según la fórmula lacaniana que lo equipara con "el discurso del Otro". En el momento mismo de la metabolización, hay un "trabajo" de inscripción que cincela represivamente un mensaje jamás completamente indescifrable, pero el cual no permanece indemne ni somete a la criatura a una sujeción unilateral. Precisamente, en esa grieta de la represión "originaria" es donde se constituye el inconsciente. El equívoco es constitutivo del inconsciente. La interpretación psicoanalítica no podría, ahora se ve mejor por qué, ser confundida con una hermenéutica del sentido original. 
La ambivalencia de la metabolización habilita una crítica de la idea lacaniana de inscripción del sujeto en el campo del Otro, sin devenir por eso en "psicología". Para un enfoque laplancheano siempre hay un desfasaje entre el proceso asimétrico de seducción y la construcción del sujeto que jamás elimina un margen de contingencia. En un "balance" del aporte de Lacan al psicoanálisis, Bleichmar estimó las contracaras de un pensamiento forjador de contribuciones originales al saber post-freudiano. Mas ese ajuste de cuentas también la induce a destacar que "cuando el afán de universalidad hace perder de vista que el psicoanálisis se instituye sobre el horizonte de la búsqueda de la determinación de las legalidades psíquicas”, lo que se pierde de vista es que ello no puede acometerse "si no es a partir del reconocimiento de la singularidad" (Bleichmar 2006a, p. 247).

El psicoanálisis no es una teoría o filosofía del sujeto. Es más, exactamente pensado, una teoría del síntoma. Según Bleichmar, "no se puede hablar de inconciente, no se puede hablar de formación de síntomas en la infancia en sentido psicoanalítico, antes de que la represión originaria se instaure, constituyéndose a partir de ello el aparato psíquico" (1984, p. 57). Las consecuencias patógenas de esta represión productora del inconsciente son las que requieren de tratamientos simbolizantes, por los cuales será posible instituir una relación intersubjetiva no dañina, de un dolor tolerable y no paralizante, aunque siempre habitada por un malestar.

Un elemento importante de la teoría psicoanalítica desplegada por Bleichmar distingue entre el aparato psíquico (la constitución de una tópica) y la subjetividad. Mientras aquel es universal pues lo es también la diferencia traumatizante de la seducción originaria, las vicisitudes de la configuración histórica del yo y de sus lazos con el semejante en lo social -que no debería ser confundido con el otro lacaniano, de índole imaginaria- son, en buena medida, impredecibles. Bleichmar insiste en su crítica al determinismo que, en moldes distintos, gobierna las teorías kleinianas y lacanianas. Para ella el sujeto emergente en la producción del inconsciente no está definido de antemano.

La perspectiva de Bleichmar no se agota en la elaboración de una alternativa a la teoría y clínica kleinianas para el psicoanálisis de la infancia. Como destaqué antes, porque la producción del inconsciente supone un debate en el entero campo del psicoanálisis y porque hay derivaciones que perforan las barreras disciplinares. En este último movimiento teórico, Bleichmar prolonga una tradición constitutiva del psicoanálisis: exceder los territorios de la clínica en los préstamos de otros campos del saber y/o en el avance sobre los conceptos configuradores de ámbitos heterogéneos de conocimiento.

$\mathrm{Al}$ concluir su argumentación, la autora subraya que en el esclarecimiento de los momentos iniciales ("míticos") de constitución del aparato psíquico, se procede a una "historización" de la relación, en apariencia imposible, entre estructura y contingencia. Bleichmar procura evadir dos posibilidades insatisfactorias para dar cuenta de la historia subjetiva. Por un lado, un estructuralismo que anula toda agencia o metabolización productiva en beneficio de un lenguaje constituyente. Por otro lado, una concepción radicalmente contraria, nietzscheana o foucaultiana, de una batalla entre contingentes campos de fuerza que elimina las constricciones estructurales.

La opción de la psicoanalista argentina consiste en concebir una historia compatible con la fundación estructural que reorganiza de manera inevitablemente traumática la retroactividad de la experiencia subjetiva. Historia, pues, no como un relato conciliador, sino como narración siempre problemática donde repetición y transformación son inseparables (también en Bleichmar, 1994). Bleichmar señala que esta concepción es asimilable a las nuevas ideas annalistes de lo histórico según las cuales se debe pasar de una "historia-relato" a una "historia-problema". De acuerdo con esta variante historiográfica, los acontecimientos son reinscriptos en redes de interpretación que les confieren el estatus de "hechos históricos" (Bleichmar cita sobre la cuestión a François Furet y a Pierre Nora). Así las cosas, las lógicas del saber psicoanalítico y la del saber historiográfico no serían radicalmente diferentes. Ese enriquecimiento en el pensamiento de Bleichmar del extramuros del psicoanálisis con su propia trama conceptual constituye un rasgo productivo que intento precisar. La historicidad del sujeto (de su estructura psíquica, de sus simbolizaciones, de su configuración inconsciente) 
caracteriza el modo en que se desplazó más allá de la atracción lacaniana perceptible en sus primeros escritos anteriores al exilio mexicano.

Los posteriores trabajos psicoanalíticos de Bleichmar extendieron la edificación de puentes entre, por un lado, las interrogaciones de su especialidad teórica y clínica, y por otro lado, prácticas no "psi" del conocimiento social. Por ejemplo, en La fundación del inconsciente introdujo la concepción de la "economía libidinal" del vínculo entre represión y goce para preguntarse inmediatamente: “¿No es todo este siglo un paradigma, en el nivel de la Historia, de tales oscilaciones llevadas a sus polos de máxima tensión?" (Bleichmar, 2002a [1993], p. 11). En este mismo texto asomaron las contextualizaciones políticas de las elaboraciones psicoanalíticas, evidentes en la sección "Agradecimientos" que cerró el libro cuya primera edición data de 1993. Bleichmar retribuyó el apoyo de colegas e instituciones que facilitaron su trabajo, "en un mundo que algunos pretenden homogéneamente signado por la lucha despiadada y el individualismo de gradado", a la vez que reconoce a su pareja Carlos Schenquerman el "sostener una vida en la cual la renuncia a la utopía no quede signada por el abandono de la esperanza" (Bleichmar, 2002a [1993], p. 16). Las evidencias de un desplazamiento de temas psicoanalíticos a un orden extraclínico pero no radicalmente diferente son más nítidas en este libro que en En los origenes del sujeto psíquico. Un tema habitual más tarde, como el uso de referencias de la atroz historia del genocidio nazi se presenta cuando refiere un caso de la "culpa del sobreviviente" y cita el relato clásico de Primo Levi, Los hundidos y los salvados, y luego el Hier ist kein Warum problematizado por Claude Lanzmann en un trabajo ligado a Shoah, o cuando reitera la similitud entre la historia infantil con la "historia de los pueblos sin historia" concebida por una nueva historiografía (Bleichmar, 2002a [1993], p. 72, 89, 97). También allí, encontramos una referencia al Herbert Marcuse de Eros y civilización y su noción de "plus de represión" con el propósito de captar la novedad de un "poder sobrante" a veces ejercido desde el lugar de analista, indicación que luego será extendida en otra dirección en el concepto de "malestar sobrante" (Bleichmar, 2002a [1993], p. 65). La revista psicoanalítica que impulsó desde 1975, Actualidad Psicológica, se caracterizó por esa impronta de infatigable compromiso crítico con la propia época.

La fluidez de Bleichmar para producir conceptos en el plano metapsicológico es inseparable de la historicidad nocional con que comprende la práctica psicoanalítica. Esa propensión a generar conceptos o resituar las nociones heredadas acompaña una interrogación sobre una eventual obsolescencia del saber freudiano. Superar esa obsolescencia exige pensar su renovación frente a circunstancias distintas a las de 1900. A mediados de los años noventa, reflexionó sobre qué condiciones tornarían viable la existencia de psicoanalistas en el año 2050, una presencia que no habría que dar por descontada:

\begin{abstract}
“Antes de definir cómo serán los psicoanalistas del 2050, debemos saber si están dadas las condiciones para que haya psicoanalistas en el 2050: qué aptitudes tiene el psicoanálisis, en tanto región del conocimiento, de engendrar nuevas ideas, y qué opciones tenemos los psicoanalistas de fines del siglo XX de reproducirnos en nuevas camadas fecundas intelectualmente, son cuestiones ambas que separan el estrecho margen que puede abrirse entre el desaliento y la esperanza. Se trata de aventurar la idea de si las hipótesis, descubrimientos y desarrollos del psicoanálisis tendrán o no un lugar en el siglo XXI, o si serán derrotadas por campos más fecundos del conocimiento (...) o si, por el contrario, su incapacidad de enfrentar las nuevas tareas del siglo y el agotamiento de sus enunciados lo implosionarán desde el interior hasta convertirlo en un remedo de sí mismo, que se hundirá dejando en la superficie un vacío a ser llenado por la eficiencia de mercado, no por la verdad eficiente, con la cual otras teorías intentarán rápidamente reemplazarlo" (Bleichmar, 1996, p. 24).
\end{abstract}

El volumen Clínica psicoanalítica y neogénesis (2001 [1999]), publicado por vez primera en 1999, recuperó materiales de un seminario dictado durante los años precedentes en el Hospital "Ricardo Gutiérrez" de la ciudad de Buenos Aires. Ese libro prolongó y profundizó la huella ética de la práctica psicoanalítica de Bleichmar, definida en los años noventa alrededor del "semejante" en la trama subjetiva contemporánea. El "Prólogo" enunció una visión apesadumbrada pero no derrotista de la realidad, pues tal sensibilidad dificultaría la transmisión de un legado para las generaciones pertenecientes al siglo venidero. Bleichmar imaginó una lectura de las obras psicoanalíticas cinco siglos más tarde y se preguntó si entonces se diría 
que la vocación por "conocer y transformar algo de la condición humana" sería atribuible al psicoanálisis, que así merecería alguna dignidad. Justamente, la noción de "neogénesis" alude a la concepción de nuevas simbolizaciones, la construcción de representaciones innovadoras que consientan el planteo de alternativas vitales. Sólo así, subrayó, el psicoanálisis será alguna vez más que un desecho teórico. Numerosas premisas ideológicas, como la ecuación entre padre y ley, eran ya insostenibles (Bleichmar, 2002c). Es con este contexto de comprensión político-cultural del psicoanálisis que Bleichmar reclamó una rearticulación de la teoría y la práctica, una disociación negativa que propuso superar sin renunciar a las discusiones propias del campo freudiano. Es con este talante que recibió la crisis argentina del 2001 y ante la cual comenzó una producción teórica y ensayística cuyo vértice fue Dolor país (esa producción, rearticulada en 2007 en su libro Dolor país y después, continuada en No me hubiera gustado morir en los 90 [Bleichmar, 2006b] no puede ser tratada aquí). En la próxima sección desarrollaré las exploraciones de Bleichmar respecto de la masculinidad y su condición paradojal que, entiendo, participan -sin desmedro de su emplazamiento clínico- del mismo espíritu de interrogación por el malestar en la cultura contemporánea.

Pero antes de proceder a la lectura crítica de las intervenciones psicoanalíticas de Bleichmar sobre las masculinidades, me interesa hacer una brevísima referencia a su ubicación como teórica. Bleichmar proviene de una formación teórica de izquierda. Allí, el psicoanálisis retiene un rol crucial, pero en modo alguno es el único. También, está presente el marxismo, con vigorosas inflexiones de la Escuela de Frankfurt (principalmente, Marcuse) y del pensamiento sartreano.

Desde mediados de la década de 1980, Bleichmar desarrolló con perseverancia su compromiso con el psicoanálisis (en sus prácticas teóricas, clínicas y académicas), pero nunca cedió en su deseo político, que si no fue el mismo de diez años atrás - aún continuó orientado por el horizonte de la igualdad y la justicia social. En esa matriz, incorporó nuevas lecturas como las de Emmanuel Lévinas y Cornelius Castoriadis. Sus vinculaciones intelectuales persistieron en el cultivo de solidaridades en la izquierda y el progresismo. Una articulación significativa la relacionó con el grupo ligado a la revista Topía, donde publicó numerosos escritos en los que intersectó el psicoanálisis con lo político. Este espacio es particularmente relevante porque brindó un clima de interrogación social del saber psicoanalítico, una conexión característica de varias publicaciones de la editorial ligada a la revista, que editó dos de sus libros en la colección "Psicoanálisis, Sociedad y Cultura" (Bleichmar, 2009a y 2009b).

\section{LAS MASCULINIDADES PARADOJALES}

El libro Paradojas de la sexualidad masculina (2006a) fue el último libro orgánico aparecido en vida de Bleichmar. Con posterioridad, se publicaron recopilaciones de artículos, algunas ya citadas. También, se editaron sus cursos en varios volmenes, uno de los cuales será referido en esta sección en la medida en que aporta información sobre el tratamiento de las masculinidades. Paradojas constituye un documento significativo en el que se congregan los dos elementos característicos de su pensamiento sobre las incertidumbres inherentes a las cuestiones de género, sexo, sexualidad y deseo. Por un lado, la deconstrucción teórica de los moldes sedimentados en prácticas de imposición política de modelos jerarquizantes. Por otro lado, la insuficiencia de su mero cuestionamiento cuando las formas determinadas asumidas en las biografías particulares producen sufrimientos que conducen a la consulta clínica. Este segundo elemento es el que introduce una presión en la teorización psicoanalítica que no suele hallarse de la misma manera en la elaboración filosófica o en la reconstrucción historiadora. En este artículo, voy a eludir una consideración atenida a los desafíos estrictamente clínicos, que han sido abordados por estudios como el de Facundo Blestcher (217). Bleichmar formula esa doble exigencia del siguiente modo:

“Cada vez que un enunciado es puesto en cuestión por los nuevos modos de la subjetividad, nos obliga a una revisión de sus fundamentos, en razón de que, fuera de todo relativismo, los núcleos de verdad que posee no pueden ser expulsados junto con las formas de subjetividad de los tiempos en los cuales fueron acuñados" (2006a, p. 9). 
Bleichmar supone que esa tarea es posible. Al reconocer la efectividad de los "núcleos de verdad", como en toda teoría realmente crítica, no se apela a una realidad exterior a la historia, esencial. Pero no por eso el psicoanálisis no está condenado de antemano a constituirse en una tecnología de dominación. Las dificultades reveladas por el gremio y teorías psicoanalíticas ante la crisis de los paradigmas de la subjetividad en la modernidad avanzada son múltiples y no son soslayables como obstáculos particulares. Los episodios documentables de defensa psicoanalítica del binarismo sexual, la heterosexualidad compulsiva, el orden patriarcal-edípico, el bimorfismo genital, la familia binaria, el diagnóstico de perversión ante el desvío de una norma presuntamente universal, en otros, perduran como problemas sistemáticos del pensamiento psicoanalítico y de sus prácticas. Bleichmar parte de un juicio definido: el "anquilosamiento" del psicoanálisis ante las complejidades del sufrimiento ocasionado por los paradigmas conceptuales y las prácticas con ellos conectadas en el escenario contemporáneo.

La clave del aporte psicoanalítico dentro del panorama de las ofertas teóricas actuales consiste en sostener una problematización conceptualizada sobre las dimensiones pulsionales y sintomáticas de las experiencias de la sexualidad y el deseo. Esas dimensiones poseen, ciertamente, una raigambre ideológica en el psicoanálisis cuando es menoscabado como una ontología del sujeto. Pero el carácter ideológico no disuelve su eficacia como "verdad". Por el contrario, Bleichmar sostiene que "la ideología otorga estatuto de verdad a ciertos enunciados" (2006a, p. 46, 216), donde por verdad debe entenderse la eficacia sobre las encrucijadas subjetivas. Al respecto es aconsejable diferenciar, por un lado, las exigencias de la crítica y la historización de, por otro lado, los desafíos de las matrices simbólico-prácticas que producen consecuencias subjetivas en quienes se acercan a la clínica para enfrentar las presiones, a menudo atroces, con que el cisheteronormativismo somete a cuerpos y subjetividades.

Un primer aspecto del enfoque de Bleichmar consiste en apelar a las aproximaciones antropológicas de la multiplicidad de accesos culturales al "hacerse hombre", para retomar el título de un influyente estudio de David Gilmore (1994). La "incorporación" de la virilidad a través de rituales en los que la misma se transmite de adultos a adolescentes, en una lógica de masculinización dentro de una trayectoria previa donde los niños pertenecen a una sociabilidad femenina, habilita extender el significado de la concepción ampliada de la seducción para la teoría psicoanalítica contemporánea.

El mito formativo del Edipo es revisado en términos de una "asimetría constitutiva" de la criatura y la persona adulta munida de inconsciente y sexualidad. Las "teorías sexuales infantiles" dejan de ser entonces modelos ontogenéticos, para asumir su carácter fantasmático orientado a proveer una defensa ante la situación de seducción generada por el cuidado adulto. Bleichmar sostiene que existen al menos dos maneras de relacionar el psicoanálisis con esas teorías sexuales infantiles. Una es naturalizarlas y emplearlas como modelos psicologizantes de la normalidad ante la cual se definen las "perversiones", o lo que es lo mismo, los desvíos en la asunción de la normalidad. Otra distinta consiste en asumir críticamente sus eficacias en tanto investimientos pulsionales y fantasmáticos, inscriptos todos en las transformaciones histórico-culturales de la época y, por ende, arbitrarios.

"Se plantea aquí la diferencia entre la concepción psicoanalítica de cuño psicológico que pone el acento en lo desconocido, que propone a las figuras parentales como reasegurantes, haciendo pasar a un segundo plano su carácter sexuado, y la perspectiva psicoanalítica para la cual el investimiento libidinal de objeto y su fantasmatización ocupan un lugar central en la configuración de la angustia y en los destinos sexuados del sujeto" (Bleichmar, 2006a, p. 62).

Se despliega, entonces, un contenido sexual y un "mensaje" cargado eróticamente que no es siempre genital (2006a, pp. 81, 84, 99), por el cual se cuestionan los ya inverosímiles tiempos freudianos de la evolución sexual (2006a, p. 94). La "identidad de género" es, entonces, previa a lo sexual en clave genital e incluso a la asunción por el yo de la diferencia anatómica. La identidad de género no constituye el núcleo de la sexualidad en psicoanálisis, "ya que su estatuto [el binarismo femenino/masculino] no corresponde al del inconsciente en la legalidad que lo rige”, el que es compatible con la contradicción (2006a, p. 79). En este sentido, la maquinaria mítica del Edipo deja de constituirse en dispositivo normativizante-familiarista-heterosexista 
para ser concebida como la "instauración de una prohibición que la cultura ejerce para poner coto a la apropiación del cuerpo del niño como lugar de goce del adulto" (2006a, p. 81), más allá del binarismo y la conciencia. Ese goce del adulto tiene un alcance transhistórico (2006a, p. 87-88).

En la misma tesitura, Bleichmar subraya la inadecuación de plegarse al historicismo radical de algunas vertientes del feminismo. En efecto, es constitutivo del psicoanálisis distinguir esa dimensión históricoempírica de otra dimensión que, a falta de un mejor término, podemos denominar estructural. La constitución de las subjetividades es inequívocamente histórica. Obedece a las contingencias de una situación epocal. No ocurre lo mismo con la constitución del psiquismo, esto es, de los procesos en los cuales se incorporan las funciones tópicamente diferenciadas en una situación de asimetría en que las pequeñas criaturas están a merced de individuos hablantes y sexuados. He aquí la formulación más explícita de esa distinción y la tarea que involucra para el psicoanálisis:

"La producción de subjetividad es del orden histórico, social y político; alude a los modos con los que cada sociedad determina las formas con las cuales un sujeto se constituye como sujeto social y se inserta en el mundo en que le toca vivir. La constitución del psiquismo, por su parte, intenta cercar un conjunto de variables que implican cierta universalidad, cuya permanencia se sostiene más allá de ciertos cambios en la producción de sujetos históricos. Para trabajar sobre estas transformaciones es necesario entonces analizar las cuestiones vinculadas a la constitución del psiquismo y considerar su relativa superposición y diferenciación con la producción de la subjetividad" (2006a, p. 83).

Una distinción central en la reescritura de la teoría psicoanalítica de la sexualidad consiste en retomar la distinción entre diversidad de género y diferencia sexual. De acuerdo a Bleichmar, la asunción de una peculiaridad de género se realiza sin conocimiento de la función sexual y da por inadecuada la antigua teoría freudiana de la "bisexualidad constitutiva", incluso si esa bisexualidad es interpretada -como corresponde hacerlo- en la oposición de orientaciones pulsionales activas y pasivas. El binarismo como tal es una dificultad a la que es preciso sustraerse pues existen n posibilidades de una producción de identidad de acuerdo a los mandatos sociales y culturales.

La interrogación por la masculinidad no se resuelve en la asunción post-edípica de la diferencia sexual y la orientación del deseo, en una fase condicionada por el descubrimiento de la posesión o no del pene. Para las significaciones culturalmente vinculantes, esa posesión o su no posesión pone en circulación la incertidumbre de una transmisión de masculinidades y la tensión con la versión hegemónica donde la posición del pene involucra una virilización según la cual "al reforzamiento de la potencia mediante la recepción de un pene que le incremente al varón las posibilidades no sólo de goce sino de hacer gozar a la mujer, marcando la insuficiencia del propio pene para lograrlo" (2006a, p. 64; cursivas en el original).

Es crucial tener presente que esta lógica es histórica, modificable, pero efectiva en la producción de determinaciones subjetivas y deseantes. Se la puede denominar también hegemónica y discutible, e incluso, cuestionable desde los movimientos sociales orientados a la multiplicación de configuraciones del nexo sexo-género-deseo. Pero aun si la génesis de la "sexualidad" es retrospectiva y, tal como se evidencia con la masculinidad en la que su potencia de órgano coexiste con una fantasmática de recepción de una penetración virilizadora, mantiene su efectividad siempre incierta y paradojal. En efecto, para asumir la posición masculina identificada es preciso recibir esa potencia, ser acreditado por la recepción de semen (como en algunos rituales estudiados por la antropología) o el pene, así sea como fantasía.

¿Hasta dónde la reescritura por Bleichmar de la teoría psicoanalítica se revela apta para exceder una dificultad en apariencia constitutiva del saber freudiano para pensar críticamente su época, sin aplicar normativizaciones violentas sobre las subjetividades ajenas a la fantasmática cisheterosexual? De acuerdo al argumento laplancheano de Bleichmar, la identidad se constituye desde la propuesta del "otro" y las contingencias determinadas de las metabolizaciones. De esas situaciones se generan producciones de subjetividades y fantasmas, irreductibles a los condicionamientos universales pero inseparables de ellos. La perversión ya no es la denegación de la "castración” materna ni la identificación como falo que la complete. 
Es el goce desubjetivizante del otro. En un giro polemizable, Bleichmar lo vincula con el sadomasoquismo, cuyas fronteras con formas de disfrute y goce son equívocos.

La importancia del libro de Bleichmar reside en las innovaciones teóricas que he esquematizado, pero también en la honestidad con que despliega un eje capital de su discusión a propósito de una dificultad analítica y conceptual: las masculinidades de personas trans. El caso de mayor desarrollo es el de Gabby, antes Agustín, quien recorre un camino de la infancia a una adolescencia en que las correlaciones entre masculinidad, subjetividad y deseo de reconocimiento deben lidiar con las constricciones y sufrimientos generados por los ideales arbitrarios que, a pesar de hallarse en crisis, generan todavía un enorme dolor. Gabby estuvo en comunicación con Bleichmar mientras estaba en consulta con otro profesional de su ciudad en los años previos a la publicación de Paradojas. Conteste con temas sintetizados en párrafos previos, durante su acompañamiento Bleichmar se resistió a apelar a esas teorías sexuales infantiles naturalizadas, en los discursos psicologizantes, incluso en ciertos psicoanálisis: las fantasías de la castración, la falta de pene y las fórmulas fantasmáticas a propósito de las diferencias anatómicas.

Las novedades relativas a las configuraciones del deseo, a la transformación corporal y a los vínculos de reconocimiento, se liberan de una normativa basada en la anatomía normativizada y en correspondencias subjetivas, en contraste con las cuales supieron abrirse los discursos - tantas veces con consecuencias nefastasde los diagnósticos de enfermedad, perversión y psicosis. De hecho, la inteligencia, sensibilidad, comprensión de sí misma y de los otros, hace de Gabby una adolescente en pugna por constituirse en partícipe de su construcción como subjetividad deseante y deseada, dentro de un contexto simbólico. Este es el pasaje decisivo en el análisis de Bleichmar:

"Cuando Gabby dice que quiere que sus padres le pongan el hombre, porque se trata de un nuevo nacimiento simbólico,
alude al reconocimiento de la primogenitura y a su deseo de no producir un autoengendramiento. Y aun cuando me
solicita que en mi informe escriba 'me parece', 'sería de suponer', pone de relieve el respeto que mi palabra le merece a la
vez que su preocupación por quedar sometida no a mi conocimiento sino al poder capturante del discurso médico. (...)
No hay tampoco, respecto al reconocimiento anatómico, el empleo del mecanismo que Freud acuñara bajo el vocablo de
Verleugnung [denegación] (...). En ningún momento Gabby atribuye a la diferencia anatómica un carácter diverso de aquel
que la legalidad impone. Dice, simplemente, que su anatomía es masculina, pero que ha sido un 'error de la naturaleza',
sosteniendo que no necesariamente el ser hombre o mujer se define por la existencia del pene, sino por algo que hace a la
identidad" (2006a, p. 148).

Desechada la apelación a términos como psicosis o perversión, el propósito del tratamiento consiste en acompañar la generación de una subjetividad entre semejantes. Donde Bleichmar como psicoanalista no cede es en el plegarse a una erosión historicista -que atribuye a algunos movimientos sociales ligados a la diversidad sexual- en beneficio de una desimbolización fantasmática ilimitada, donde se pierde precisamente el desafío de lidiar con la época. Es una desimbolización que con el fin loable de combatir las opresiones normativizantes invisibilizan los maltratos, los goces desubjetivantes y generan un "desconocimiento" que "deviene un obstáculo mayor para ayudar a procesar mejor los residuos psíquicos de todo embate de la historia" (2006a, p. 152).

Un informe preparado por Bleichmar con el fin de sostener el pedido de Gabby para adecuar su anatomía a su deseo incluyó una expresión justamente discutida por la Red Transexual Argentina y otras organizaciones amigas (2006a, pp. 217-220). En un pasaje de su informe, Bleichmar señaló de manera condicional que una cirugía temprana pudo haberse realizado para evitar posteriores trastornos "tanto funcionales como psíquicos”. La Red argumentó, en mi opinión con toda razón, que ese pasaje ignoraba los sufrimientos, arbitrariedades y consecuencias traumatizantes de tales intervenciones tempranas.

La respuesta de Bleichmar fue poco convincente pues, por una parte, conocía los efectos desastrosos de tales operaciones como en el caso de John/Joan - una reasignación de sexo luego de un accidente infantil, historia que concluyó en un suicidio tras un prolongado sufrimiento-, por otra parte, el de Gabby no involucraba la intersexualidad (esta última indicación es siempre de la psicoanalista argentina). Fue ella misma quien refirió 
a un "error de la naturaleza" que debía ser subsanado. Entiendo que la afirmación en condicional de Bleichmar era innecesaria para la lógica de su planteo, aunque puede ser un indicio para la discusión probablemente insaldable, de si la incorporación de la pulsión y el síntoma en psicoanálisis no retorna siempre a la dificultad de una razón médica jamás del todo desplazada.

La disponibilidad de los cursos de Bleichmar en los años de la consulta de Gabby permite acceder a aspectos no del todo nítidos en la formulación de Paradojas. Así es que en la clase del 12 de julio de 2004, desarrollada con el título de "Transexualismo e intergénero", la psicoanalista sostuvo lo siguiente: "no estoy de acuerdo en que un niño pueda estar sin definición de sexo los primeros años de la vida. Creo que la cultura tiene que ejercer algún tipo de violencia determinante de la identidad, como lo hace siempre" (Bleichmar, 2014: 222). Desde luego, "la cultura" que ejerce esa violencia presupone una correspondencia entre sexo y género que el análisis paradojal cuestiona, pero sobre el que la razón médica parece todavía requerir una "definición de sexo". Entiendo que Gabby siguió un prolongado recorrido en la conquista de una autonomía decisoria para avanzar hacia una modificación corporal reconocida por la propia Bleichmar. Continúa, por lo tanto, incierto el diagnóstico del estatus de esa violencia, pues algunas vertientes del psicoanálisis la universalizan consagrándola- mientras otras la conceptualizan en las pautas de una teoría crítica, es decir, como mecanismo de dominio que requiere ser cuestionado. Lo problemático es que una historización como la foucaultiana, donde se elimina la dimensión del síntoma, conduce a una alternativa poco atractiva entre el historicismo radical y el cese de cualquier diálogo con el psicoanálisis.

\section{CONCLUSIONES}

En este artículo, he reconstruido el perfil intelectual de la psicoanalista y teórica Silvia Bleichmar con el propósito de pensar sus innovaciones conceptuales respecto del carácter paradojal de la masculinidad. Tal vez, convenga hablar de masculinidades paradojales. Entonces, si Freud sealó la índole paradojal de la femineidad, para un psicoanálisis de un siglo más tarde la masculinidad también deviene un dark continent que exige repensar al saber freudiano como tal sin descartar su definitiva defunción. Los efectos de dicha reflexión son aúrdesconocidos porque el conjunto del saber psicoanalítico se construyó desde dos pilares aquí cuestionados: la masculinidad como modelo respecto del cual la feminidad era un desvío posterior al descubrimiento de la diferencia anatómica

Desde una lectura creativa de Laplanche, Bleichmar generó novedades teóricas para analizar su época, tanto en las configuraciones recientes del malestar en la cultura, como en las derivas de las subjetividades "en riesgo". El tema de las masculinidades es relevante para retornar a una discusión planteada en torno a la deconstrucción, impulsada por las teorías críticas feministas mucho más allá de la problemática de las femineidades, de las configuraciones normativizantes de la subjetividad.

Gracias a una incorporación de estudios antropológicos, Bleichmar produjo una historización de las maneras en que se generan las masculinidades, reteniendo, sin embargo, los aspectos universales iluminados por el psicoanálisis. Es esencial, en ese sentido, el modo en que la psicoanalista argentina vertebró la significación para las masculinidades de la teoría de la seducción y el conjunto de mutaciones conceptuales que de allí se derivan.

Nociones decisivas como Edipo, perversión, psiquismo, subjetividad, semejante, son incorporadas en un debate abierto. Bleichmar supo conceptualizarlo en términos de asumir "un aparato psíquico abierto a lo real", esto es, "constituido a partir de inscripciones provenientes del exterior y sometidas constantemente a sus embates" (2004, p. 67). Entiendo que en la estela de una discusión desarrollada principalmente por las aspiraciones crítico-emancipatorias del feminismo y, más cerca de nuestros días, la teoría queer, la trayectoria de Bleichmar revela un trabajo incansable por hacer que el psicoanálisis participe del horizonte políticointelectual del presente. No he dejado de apuntar algunas incertidumbres que tal vez no sean solo de Bleichmar, sino quizás del psicoanálisis: su potencia para recordar las eficacias de la pulsión y el síntoma tienen 
una sombra nunca erradicada, ni erradicable, del "saber médico". Con ello, no quise plegarme al juicio de Foucault, en última instancia opuesto al psicoanálisis, sino visibilizar un debate en curso.

Quiero, por último, subrayar que sería inadecuado esperar de los textos de Bleichmar, y de todos los enunciados desde el psicoanálisis, una teoría general del sujeto. Lo mismo sucede respecto del tema específico aquí examinado. En el caso de que se hallare algún interés en el argumento desplegado, es preciso recordar que la apelación a estudios sociales e históricos para repensar la paradoja de las masculinidades contemporáneas es inseparable de la dimensión sintomática. En sentido contrario, desde prácticas ajenas al psicoanálisis, el acercamiento al conjunto de temas desarrollados en este artículo requiere considerar esa condición para evitar transposiciones violentas. Una vez asumida tal advertencia, la productividad de los diálogos se dirime en la contingencia de su calidad.

\section{RefERENCIAS BIBLIOGRÁfiCAS}

Acha, O. (2007). Freud y el problema de la historia. Buenos Aires: Prometeo Libros.

Acha, O. y Vallejo, M. (Eds.) (2010). Inconsciente e historia después de Freud. Cruces entre filosofía, psicoanálisis e historiografía. Buenos Aires: Prometeo Libros.

Arrivé, M. (2002). Lingüistica y psicoanálisis. México: Siglo Veintiuno.

Assoun, P. (1982). Freud. La filosofía y los filósofos. Buenos Aires: Paidós.

Assoun, P. (1993). Freud et les sciences sociales. París: Armand Colin.

Bastide, R. (1961). Sociología y psicoanálisis. Buenos Aires: Compañía General Fabril Editora.

Bleichmar, S. (1984). En los orígenes del sujeto psíquico. Del mito a la historia. Buenos Aires: Amorrortu.

Bleichmar, S. (1987). Jean Laplanche: un recorrido en Problemáticas. Revista Asociación Escuela Argentina de Psicoterapia para Graduados, 14, 7-29.

Bleichmar, S. (1994). Repetición y temporalidad: una historia bifronte. En Bleichmar, S. (Comp). Temporalidad, determinación, azar. Lo reversible y lo irreversible (pp. 45-75). Buenos Aires: Paidós.

Bleichmar, S. (1996). Un psicoanalista en el 2050. Topía, 16, 17-28.

Bleichmar, S. (2001 [1999]). Clinica psicoanalítica y neogénesis. Buenos Aires: Amorrortu.

Bleichmar, S. (2002 [1993]). La fundación de lo inconciente. Destinos de pulsión, destinos del sujeto. Buenos Aires: Amorrortu.

Bleichmar, S. (2002b). Dolor país. Buenos Aires: Libros del Zorzal.

Bleichmar, S. (2002c). Norma, autoridad y ley. Bases para la redefinición de una legalidad en psicoanálisis. Actualidad Psicológica, 303, 2-5.

Bleichmar, S. (2004). Ampliar los límites de la interpretación en una clínica abierta a lo real. Docta, 2(1), 65-78.

Bleichmar, S. (2006a). Paradojas de la sexualidad masculina. Buenos Aires: Paidós.

Bleichmar, S. (2006b). No me hubiera gustado morir en los 90. Buenos Aires: Taurus.

Bleichmar, S. (2007). Dolor país y después. Buenos Aires: Libros del Zorzal.

Bleichmar, S. (2009a). El desmantelamiento de la subjetividad. Estallido del yo. Buenos Aires: Topía.

Bleichmar, S. (2009b [2005]). La subjetividad en riesgo. Buenos Aires: Topía (Ed. ampliada).

Bleichmar, S. (2010). Psicoanálisis extramuros. Puesta a prueba frente a lo traumático. Buenos Aires: Entreideas.

Bleichmar, S. (2014). Las teorias sexuales en psicoanálisis. Qué permanece de ellas en la práctica actual. Buenos Aires: Paidós.

Blestcher, F. (2017). Infancias trans y destinos de diferencia sexual: nuevos existenciarios, renovadas teorías. En I. Meler (Comp.), Psicoanálisis y género: escritos sobre el amor, el trabajo la sexualidad y la violencia (pp. 21-48). Buenos Aires: Paidós.

De Certeau, M. (1995). Historia y psicoanálisis entre ciencia y ficción. México: Universidad Iberoamericana. 
Dean, T. (2002). Art as Symptom. Žižek and the Ethics of Psychoanalytic Criticism. diacritics, 32(2), 21-41.

Derrida, J. (2001). La tarjeta postal. De Sócrates a Freud y más allá. México: Siglo Veintiuno.

Enriquez, E. (1983). De la horde à l'état. Essai de psychanalyse du lien social. París: Gallimard.

Gilmore, D. D. (1994). Hacerse hombre: concepciones culturales de la masculinidad. Barcelona: Paidós.

Laplanche, J. (1973). Vida y muerte en psicoanálisis. Buenos Aires: Amorrortu.

Laplanche, J. (1983). El psicoanálisis: ¿historia o arqueología? Trabajo del Psicoanálisis, 2(5), 11-25.

Laplanche, J. (1989). Nuevos fundamentos para el psicoanálisis. La seducción originaria. Buenos Aires: Amorrortu.

Laplanche, J. (1996). La interpretación entre determinismo y hermenéutica: un nuevo planteo de la cuestión. En J. Laplanche, La prioridad del otro en psicoanálisis (pp. 135-166). Buenos Aires: Amorrortu.

Laplanche, J. y Leclaire, S. (1969). El inconsciente: un estudio psicoanalítico. En Green, A. et al. El inconsciente freudiano y el psicoanálisis francés contemporáneo (pp. 13-78). Buenos Aires: Nueva Visión.

Legendre, P. (1976). Jouir du pouvoir. París: Seuil.

Marcuse, H. (1983). Eros y civilización. Barcelona: Ariel.

Muensterberger, W. (Ed.) (1976). L'Anthropologie psychanalytique après 'Totem et Tabu'. París: Payot.

Pfister, O. (1932). El psicoanálisis y la educación. Madrid: Revista de Pedagogía.

Ricoeur, P. (1979). Freud: una interpretación de la cultura. México: Siglo Veintiuno.

Roth, M. (1995). Psycho-Analysis as History. Negation and Freedom in Freud. Ithaca-Londres: Cornell University Press.

Rüsen, J. y Straub, J. (Eds.) (1998). Die dunkle Spur der Vergangenheit. Psychoanalytische Zugänge zum Geschichtsbewusstsein. Fráncfort del Meno: Suhrkamp.

Saphouan, M. (1992). La palabra o la muerte. Buenos Aires: Ediciones de la Flor.

Schorske, C. (2001). Las excavaciones egipcias: psicoarqueología de las culturas (pp. 313-344). En C. Schorske, Pensar con la historia. Madrid: Taurus.

Zarka, Y. C. (Ed.) (2007). Jacques Lacan. Psicoanálisis y política. Buenos Aires: Nueva Visión.

Žižek, S. (1992). El sublime objeto de la ideología. México: Siglo Veintiuno.

\section{Notas}

1 Entre una vasta bibliografía: Assoun (1982 y 1993); Bastide (1961); Enriquez (1983); Muensterberger (1976); Pfister (1932); Roth (1995); Rüsen y Straub (1998); Schorske (2001). Por mi parte he intervenido en los debates sobre la cuestión en Acha (2007) y en Acha y Vallejo (2010).

2 Por ejemplo: Arrivé (2002); De Certeau (1995); Legendre (1976); Zarka (2004). 